\title{
Cyclic degradation of titanium-tantalum high-temperature shape memory alloys - The role of dislocation activity and chemical decomposition
}

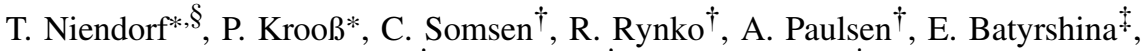 \\ J. Frenzel ${ }^{\dagger}$, G. Eggeler ${ }^{\dagger}$ and H. J. Maier ${ }^{\dagger}$ \\ *Institut für Werkstofftechnik, Technische Universität Bergakademie Freiberg \\ 09599 Freiberg, Germany \\ †Institut für Werkstoffe, Ruhr-Universität Bochum \\ 44801 Bochum, Germany \\ Institut für Werkstoffkunde, Leibniz Universität Hannover \\ 30823 Garbsen, Germany \\ ${ }_{\text {\$Thomas.Niendorf@iwt.tu-freiberg.de }}$
}

Received 29 December 2014; Accepted 16 April 2015; Published 26 May 2015

\begin{abstract}
Titanium-tantalum shape memory alloys (SMAs) are promising candidates for actuator applications at elevated temperatures. They may even succeed in substituting ternary nickel-titanium high temperature SMAs, which are either extremely expensive or difficult to form. However, titanium-tantalum alloys show rapid functional and structural degradation under cyclic thermo-mechanical loading. The current work reveals that degradation is not only governed by the evolution of the $\omega$-phase. Dislocation processes and chemical decomposition of the matrix at grain boundaries also play a major role.
\end{abstract}

Keywords: Microstructure; phase transformation; decomposition; training; $\omega$-phase.

Shape memory alloys (SMAs) have been in the focus of intensive research for decades. ${ }^{1-6} \mathrm{~A}$ fully reversible phase transformation from an austenitic high-temperature phase to a low-temperature martensitic phase can result in a substantial shape change. ${ }^{1,2}$ Three types of shape memory effects are known: The one-way and the two-way shape memory effect and pseudoelasticity. ${ }^{1,3,6}$ The first two effects can be exploited in actuator applications. Based on the transformation temperatures of the SMA under consideration, i.e., start and finish temperatures for austenite and martensite $\left(A_{\mathrm{s}}, A_{\mathrm{f}}\right.$, $M_{\mathrm{s}}, M_{\mathrm{f}}$ ), actuation can be triggered at different temperatures. ${ }^{6,7}$ For Ti-Ta- $X$ (e.g., $X=\mathrm{Al}$ ) high-temperature (HT) SMAs, $M_{\mathrm{s}}$ is adjusted to allow for actuation response under superimposed stresses in a temperature window between $150^{\circ} \mathrm{C}$ and $300^{\circ} \mathrm{C}^{8-13}$ Actuation strains for Ti-30 Ta have been shown to be highly dependent on the crystal orientation, providing exploitable transformation strains of up to $3.6 \%$ for the $\langle 011\rangle$ orientation. ${ }^{13}$ Ternary elements were shown to affect the absolute value of strains, but they do not alter the orientation dependence. ${ }^{14,15}$ A key issue for industrial applications of Ti-Ta-X HT SMAs is functional stability. Buenconsejo and co-workers showed that binary Ti-Ta alloys are prone to rapid degradation due to the evolution of the $\omega$-phase and a concomitant stabilization of the $\beta$-parent phase. ${ }^{8,10,11}$ Similarly, the enrichment of $\beta$-stabilizers in the matrix as a result of $\omega$-phase formation was demonstrated for other $\beta$-Ti-alloys. ${ }^{16}$ In an attempt to hamper $\omega$-phase evolution, Buenconsejo et al. added ternary alloying elements. ${ }^{9-11}$ They showed that tin and aluminium are the most promising elements for stabilizing Ti-Ta- $X$ alloys. ${ }^{10,11}$ Other groups indicated that the $\mathrm{Ti}-\mathrm{Ta}-\mathrm{Zr}$ and $\mathrm{Ti}-\mathrm{Ta}-\mathrm{Y}$ systems may also represent potential HT SMA candidates. ${ }^{17,18}$ Thermal and functional stability of Ti-Ta- $X$ alloys have mostly been studied for short ageing times or a limited number of cycles. ${ }^{8-11} \mathrm{Ti}-27 \mathrm{Ta}-5 \mathrm{Al}$ was shown to be stable for up to 20 thermal cycles, where the maximum test temperature was about $250^{\circ} \mathrm{C}^{10}$ Experiments conducted on Ti-30Ta and $\mathrm{Ti}-30 \mathrm{Ta}-3 \mathrm{Al}$ in related studies revealed that changes in test

$\S_{\text {Corresponding author. }}$

This is an Open Access article published by World Scientific Publishing Company. It is distributed under the terms of the Creative Commons Attribution 4.0 (CC-BY) License. Further distribution of this work is permitted, provided the original work is properly cited. 
procedure like employing a higher number of cycles at higher temperatures or long-term creep testing can lead to severe functional degradation. ${ }^{12,13,19}$ In case of cyclic thermo-mechanical loading, the rate of degradation was strongly reduced by $\mathrm{Al}$ additions, but qualitatively a similar degradation behavior was found. ${ }^{13}$ In addition, it was shown that transformation strain capability can be restored by short-time annealing treatments. ${ }^{12,13}$ However, the microstructural evolution in $\mathrm{Ti}-\mathrm{Ta}-X$ alloys associated with thermo-mechanical cycling and thermal recovery treatments was not addressed. The objective of the present study was to investigate the elementary microstructural mechanisms that are responsible for the degradation of Ti-Ta- $X$ HT SMAs subjected to different loading conditions.

Dogbone-shaped tensile specimens with a nominal gauge length of $55 \mathrm{~mm}$ and a cross section of $2 \mathrm{~mm} \times 1.5 \mathrm{~mm}$ were prepared from polycrystalline Ti-30Ta and Ti-30Ta-3Al (in at.\%) sheet material using electro-discharge machining (EDM). The Ti-Ta- $(\mathrm{Al})$ alloys were produced using highpurity $\mathrm{Ti}$, Ta and $\mathrm{Al}$ feedstock for vacuum arc melting. After homogenization annealing, sheets were produced by rolling. A final recrystallization annealing was carried out at $1000^{\circ} \mathrm{C}$ for $10 \mathrm{~min}$ followed by water quenching. Further details on material preparation and testing have been published elsewhere. ${ }^{4,20}$ Transmission electron microscopy (TEM) using a FEI Tecnai F20 operating at $200 \mathrm{kV}$ was employed to study the microstructural evolution in thin foils prepared from the gauge section of the samples. The microscope was equipped with an energy dispersive spectroscopy (EDS) unit and a high angle annular dark field detector (HAADF). The HAADF detector was used in combination with scanning transmission electron microscopy (STEM). The TEM specimens were micro-machined using a focused ion beam (FIB; Quanta $2003 \mathrm{D})$.

In order to overcome the high susceptibility of Ti-Ta- $X$ alloys to fast functional degradation, a short-time annealing for dissolution of the $\omega$-phase has been proposed in previous studies. ${ }^{12,13}$ In order to evaluate the effect of a short annealing period after each cycle, a Ti-30Ta-3Al sample was subjected to 240 thermal cycles. Thermal cycling was conducted in between $30^{\circ} \mathrm{C}$ and $400^{\circ} \mathrm{C}$ with a heating/cooling rate of $0.66^{\circ} \mathrm{C} \mathrm{s}^{-1}$. Following each cycle, the sample was rapidly heated within $10 \mathrm{~s}$ to $600^{\circ} \mathrm{C}$, annealed for $5 \mathrm{~s}$ and cooled down within $10 \mathrm{~s}$ to $400^{\circ} \mathrm{C}$ and then exposed to the next thermal cycle. Figure 1 shows representative temperature-strain cycles obtained with a bias stress of $100 \mathrm{MPa}$. Obviously, the temperature-strain behavior remains fairly stable, showing no strong decreases of transformation temperatures and transformation strains. In order to allow for a more detailed evaluation of the functional stability in terms of transformation temperatures, Fig. 2 depicts the evolution of $\mathrm{A}_{s}, A_{\mathrm{f}}$ and $M_{\mathrm{s}}$ as well as the evolution of transformation

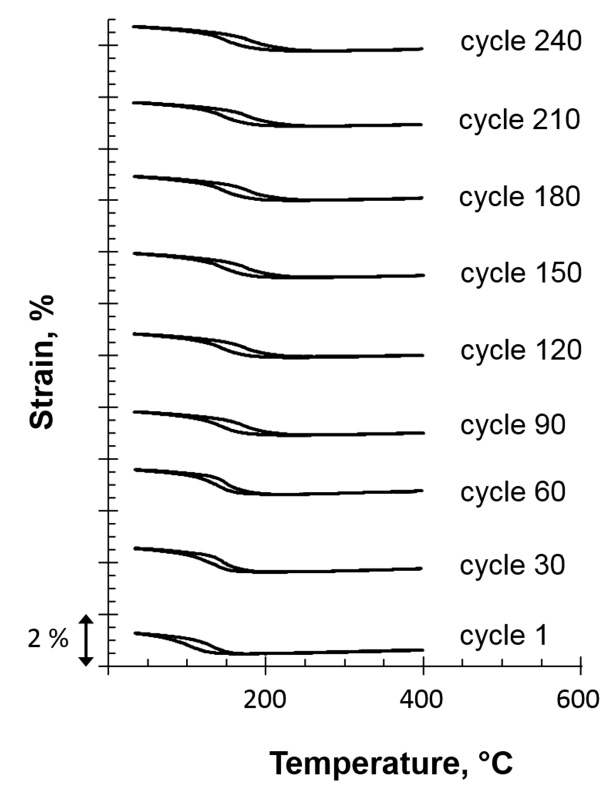

Fig. 1. Representative strain-temperature curves obtained for Ti-30Ta-3Al. Following each cycle the specimen was subjected to a short-time annealing at $600^{\circ} \mathrm{C}$ in order to suppress $\omega$-phase evolution. See main text for details.

strain as a function of cycle number. In previous work a strong decrease in transformation temperatures occurred after each cycle, ${ }^{12,13}$ which was triggered by the nucleation and growth of $\omega$-phase particles. In contrast, the transformation temperatures for the current $\mathrm{Ti}-30 \mathrm{Ta}-3 \mathrm{Al}$ sample increase up to the 100th cycle. Additionally, transformation strains slightly increase within the first 30 cycles. This effect may be partly related to the increased effective undercooling due to higher transformation temperatures. Clearly, this indicates a gradual change in microstructure. For comparison, data from a sample showing functional degradation due to $\omega$-phase formation is included in Fig. 2. The TEM micrographs and the corresponding selected area electron diffraction pattern

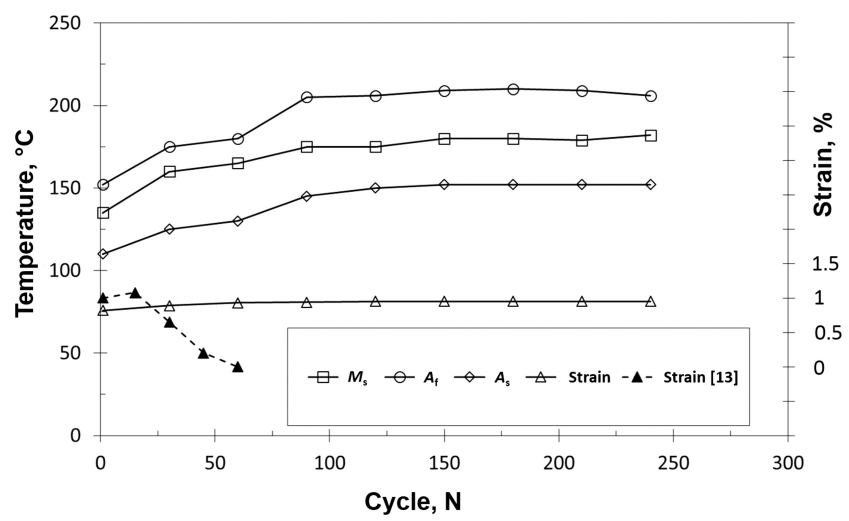

Fig. 2. Evolution of transformation temperatures and strains for the Ti30Ta-3Al sample shown in Fig. 1. For comparison, data for a sample showing rapid degradation induced by $\omega$-phase evolution (recompiled from Ref. 13) have been included. 


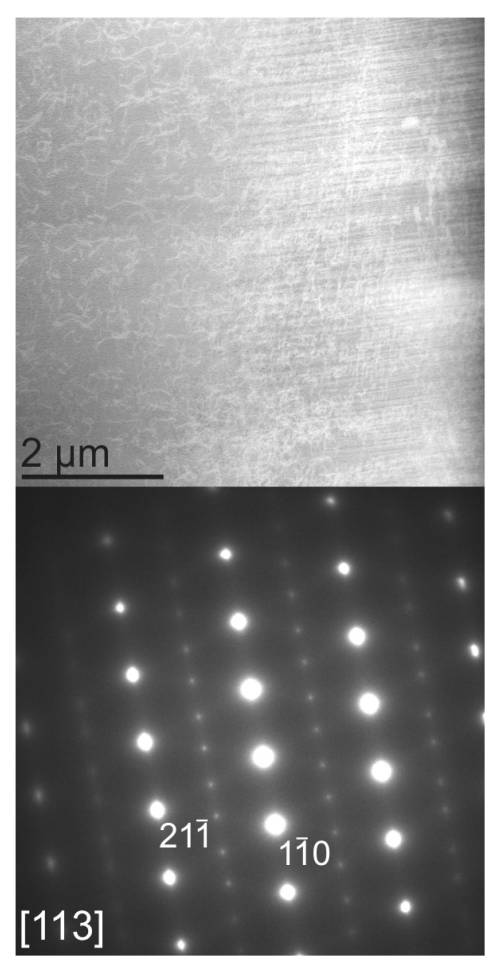

(a)

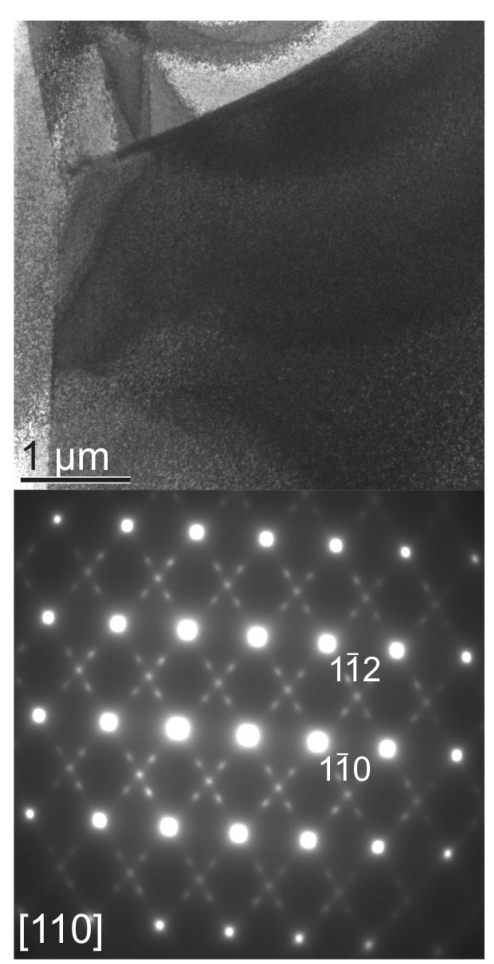

(b)

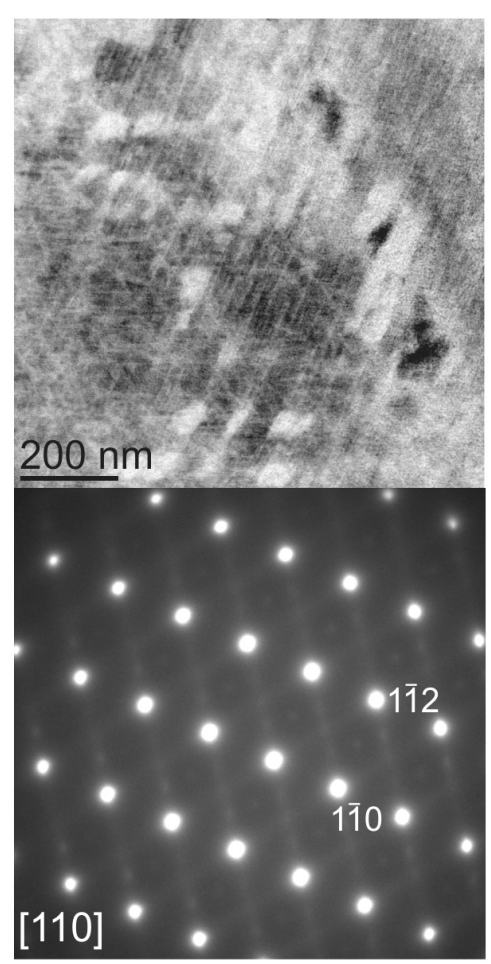

(c)

Fig. 3. TEM micrographs depicting microstructures of Ti-30Ta and Ti-30Ta-3Al samples after different thermo-mechanical loading histories. (a) STEM HAADF image for Ti-30Ta-3Al following a load increase test (maximum stress: $300 \mathrm{MPa}$ ). Dislocations appear in white. The diffraction pattern reveals no traces of $\omega$-phase, but $1 / 2\langle 211\rangle$-reflections of $\alpha^{\prime \prime}$-martensite are clearly visible. (b) TEM bright-field image of Ti-30Ta after 12 cycles in a test employing slow heating/cooling rates (maximum stress: $100 \mathrm{MPa}$ ). The corresponding diffraction pattern features faint 1/3 $\langle 211\rangle$ type reflections of the $\omega$-phase and $1 / 2\langle 211\rangle$ type reflections of martensite. (c) STEM HAADF image for Ti-30Ta after fatigue including short recovery treatments. Dislocations are visible as white features. The diffraction pattern reveals faint $1 / 3\langle 211\rangle$ type reflections of the $\omega$-phase and faint $1 / 2\langle 211\rangle$ and faint $1 / 2\langle 110\rangle$ type reflections of martensite. See main text for details.

(SAED) presented in Fig. 3 (STEM: 3(a) and 3(c), TEM: $3(\mathrm{~b})$ ) reveal that a complex interplay of different elementary mechanisms is responsible for the observed thermo-mechanical responses. It is important to note, that the results shown only highlight active mechanisms. Quantitative analyses evaluating the role of $\mathrm{Al}$ will be provided in future work. Figure 3(a) depicts a STEM HAADF image showing the microstructure of a sample that had been subjected to a load increase test (data shown in Ref. 13). The final loading cycle of the load increase test comprised a superimposed stress level of $300 \mathrm{MPa}$. The total number of cycles was 5 , so that the overall dwell time of about $2 \mathrm{~min}$ in the critical temperature regime $\left(250^{\circ} \mathrm{C}\right.$ to $\left.400^{\circ} \mathrm{C}\right)$, in which the $\omega$-phase forms ${ }^{13}$ was low. Hence, only $1 / 2\langle 211\rangle$ type reflections of $\alpha^{\prime \prime}$-martensite appear in the SAED shown in Fig. 3(a). However, as seen in the STEM image in Fig. 3(a), a high dislocation density is present (white features). This dislocation activity leads to an accumulation of irreversible strains during thermal cycling. Figure 3(b) shows a TEM bright field image together with the corresponding SAED pattern as typically observed in Ti-30Ta after 12 slow heating/cooling cycles. These tests are characterized by a high accumulated dwell time in the critical temperature regime. ${ }^{8-11}$ Note that all cycling experiments were performed under a superimposed stress of $100 \mathrm{MPa}$. As the dwell time in this case was $90 \mathrm{~min}$ (see Ref. 13), pronounced $\omega$-phase evolution is found (Fig. 3(b)) as revealed by the characteristic 1/3 $\langle 112\rangle$ type reflections in the SAED pattern.

As demonstrated earlier, short-time annealing leading to the dissolution of the $\omega$-phase in Ti-30Ta-3Al, can fully restore the initial transformation capability in the subsequent thermal cycle. ${ }^{10,13}$ By contrast, the microstructural condition following sequential recovery treatments (i.e., after each 12th cycle) is significantly different. The micrograph shown in Fig. 3(c) reveals the presence of more than one single degradation mechanism. Traces of slip activity are visible in the STEM micrograph. The corresponding SAED pattern reveals traces of the $\omega$-phase seen by a faint intensity at the $1 / 3\langle 112\rangle$ spot of the SAED pattern. In the sample, which has been cycled for an additional cycle after four dozens of the cycling/recovery sequence, ${ }^{13} \omega$-phase evolution appears to be more rapid than in the as-rolled condition. This is in good agreement with data on the evolution of the temperaturestrain response published previously. ${ }^{13}$ 


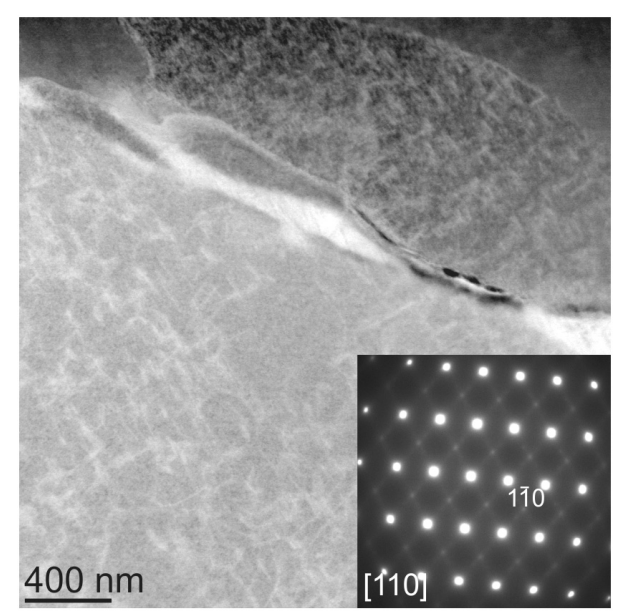

(a)

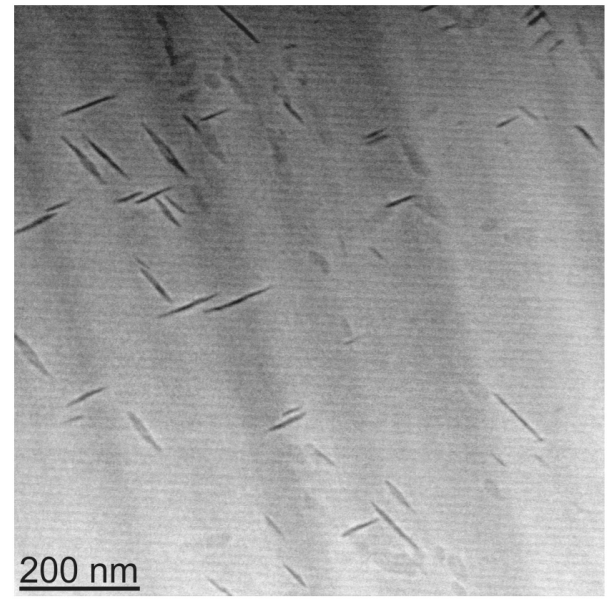

(b)

Fig. 4. TEM micrographs from Ti-30Ta-3Al after 240th cycles. (a) STEM HAADF image. Dislocations are visible in white. The diffraction pattern reveals faint $1 / 3\langle 211\rangle$ type reflections of the $\omega$-phase and faint $1 / 2\langle 211\rangle$ type reflections of martensite. Grain boundary precipitates are visible. (b) STEM HAADF image dominated by atomic number $Z$-contrast showing additional precipitates in the grain interior.

Figure 4(a) is representative for the microstructure at the end of the test procedure shown in Fig. 1. The grain boundary depicted in the center of the STEM image is decorated with fairly large precipitates of different composition. As has already been shown after creep testing for Ti-30Ta, ${ }^{19}$ Ti-rich and Ta-rich precipitates appear indicating a decomposition. Based on EDS results obtained in the current study the Ti-rich precipitates were enriched in Ti up to $90 \%\left(\mathrm{Ti}_{90.2} \mathrm{Ta}_{4.7} \mathrm{Al}_{5.1}\right.$, dark areas on the grain boundary in Fig. 4(a)), indicating the formation of $\alpha$-phase. For the Ta-rich precipitates (light areas on the grain boundary in Fig. 4(a)) a chemical composition of $\mathrm{Ti}_{36.8} \mathrm{Ta}_{60.6} \mathrm{Al}_{2.6}$ was determined. Still, analyses of compositions and structures on a statistical basis has to be provided in future work. The current type of fatigue related decomposition of Ti-Ta-X HT SMAs has so far not been reported in literature as the functional fatigue associated with the appearance of $\omega$-phase proceeds more rapidly. ${ }^{8,12}$ As shown in the present study, another deterioration mechanism comes into play, related to the formation of Ti-rich precipitates ( $\alpha$-phase), when the evolution of the $\omega$-phase is suppressed. Whether the $600^{\circ} \mathrm{C}$ recovery annealing promotes $\alpha$-phase formation cannot be decided, yet. Further analyses of the time-temperaturetransformation behavior of $\mathrm{Ti}-\mathrm{Ta}-X$ alloys is required to clarify this question.

In addition to precipitation phenomena at grain boundaries, the formation of very fine precipitates in the grain interiors could also be observed, cf. Fig. 4(b). A small camera-length of $50 \mathrm{~mm}$ was chosen to obtain the STEM HAADF image, and the contrast in Fig. 4(b) is dominated by changes in mass density known as atomic number $(Z)$-contrast. Based on EDS results (not shown here) these precipitates seem to be enriched in $\mathrm{Ti}$ as well. In chemical composition they are similar to the precipitates observed on the grain boundaries. Further characterization of details regarding precipitation is of high importance. However, this is clearly beyond the scope of the current work and will be subject of a follow-up study. Figure 4(a) suggests that there is some dislocation activity, which would provide for ample nucleation sites. There are two reasons for a less intense dislocation activity in this condition. One is the lower stress of $100 \mathrm{MPa}$, as compared to a maximum stress of $300 \mathrm{MPa}$ used in the experiment corresponding to Fig. 3(a). The second is associated with the $600^{\circ} \mathrm{C}$ recovery treatment, which also promotes a decrease of dislocation density. Dislocation arrangements induced by thermo-mechanical loading can trigger precipitation inside individual grains, as shown in Fig. 4(b). In view of these drastic changes in the evolution of microstructure in $\mathrm{Ti}-\mathrm{Ta}-X$, the sensitivity of temperaturestrain responses to intermediate short-time recovery annealing is not surprising. Within the initial 100 cycles, the dislocation density steadily increases and precipitation at grain boundaries sets in. Subsequently, both processes seem to saturate. The decomposition of the alloy into Ti-rich and Tarich precipitates (at grain boundaries) and the formation of Ti-rich particles (in grain interiors) clearly affects the phase transition. Furthermore, dislocations are accompanied by stress fields and, thus, the overall elastic strain energy increases with increasing dislocation density. ${ }^{21,22}$ This results in an increase of transformations temperatures, cf. Fig. 1. As evolution of Ti-rich precipitates and concomitant enrichment of Ta in the matrix should lead to a decrease of transformation temperatures, ${ }^{10,16}$ this is supposed to be less influential in the current case. In consequence, the increase in dislocation density as revealed by TEM analyses is expected to be the dominant mechanism leading to the observed increase of transformation temperatures. The fact that dislocations affect 
the strain-temperature hysteresis is also known from conventional training treatments. ${ }^{23,24}$

Based on the findings presented in the current and previous studies, ${ }^{12,13}$ the development of a new generation of Ti-Ta- $X$ HT-SMAs can be envisaged. This requires a new alloy design, which suppresses or delays the formation of $\omega$ - and $\alpha$-phases. Suitable recovery treatments have to be identified in parallel, allowing for restoration of the initial properties. Finally, the matrix has to be strengthened to a level that suppresses dislocation activity without hampering the martensitic transformation.

The current study investigated elementary microstructural mechanisms responsible for functional degradation of $\beta$-type Ti-Ta-(Al) HT SMAs. The results clearly indicate that a combination of different processes is responsible for the changes in transformation temperatures and transformation strains, and thus, for functional degradation during thermomechanical cycling. The microstructural evolutions occurring along different strain-temperature-time paths could be identified. In addition to the well-known formation of the $\omega$-phase and the associated stabilization of the $\beta$-phase, dislocation activity and the precipitation of $\mathrm{Ti}^{-}$and Ta-rich phases contribute to the overall degradation behavior. Further efforts to improve $\mathrm{Ti}-\mathrm{Ta}-(\mathrm{Al})$ alloys must take this microstructural complexity into account in order to develop stable HT SMAs for a robust use in engineering.

\section{Acknowledgments}

Financial support by DFG within the Research Unit Program "Hochtemperatur-Formgedächtnislegierungen" (Contract Nos.
NI1327/3-1, MA1175/34-1, EG101/22-1 and FR2675/3-1) is gratefully acknowledged.

\section{References}

1. K. Otsuka and X. Ren, Progr. Mater. Sci. 50, 511 (2005).

2. K. Otsuka et al., Phil. Mag. 4514 (2011).

3. N. B. Morgan, Mater. Sci. Eng. A 378, 16 (2004).

4. J. Frenzel et al., Acta Mater. 58, 3444 (2010).

5. Y. Sutou et al., Acta Mater. 57, 5759 (2009).

6. D. Lagoudas (Ed.), Shape Memory Alloys - Modeling and Engineering Applications (Springer, New York, 2008).

7. J. Ma, I. Karaman and R. D. Noebe, Int. Mater. Rev. 55, 257 (2010).

8. P. J. S. Buenconsejo et al., Acta Mater. 57, 1068 (2009).

9. P. J. S. Buenconsejo, H. Y. Kim and S. Miyazaki, Acta Mater. 57, 2509 (2009).

10. P. J. S. Buenconsejo, H. Y. Kim and S. Miyazaki, Scripta Mater. 64, 1114 (2011).

11. H. Y. Kim et al., Mater. Sci. Eng. A 528, 7238 (2011).

12. T. Niendorf et al., Funct. Mater. Lett. 7, 1450042 (2014).

13. T. Niendorf et al., Mater. Sci. Eng. A 620, 359 (2014).

14. H. Y. Kim et al., Acta Mater. 54, 2419 (2006).

15. S. Miyazaki, H. Y. Kim and H. Hosoda, Mater. Sci. Eng. A 18, 438 (2006).

16. Y. Al-Zain et al., Acta Mater. 60, 2437 (2012).

17. X. H. Zheng et al., J. All. Comp. 539, 144 (2012).

18. X. H. Zheng et al., Scripta Mater. 68, 1008 (2013).

19. R. Rynko et al., Int. J. Mater. Res. 106, 331 (2015).

20. J. Zhang et al., Int. J. Mater. Res. 105, 156 (2014).

21. J. Dadda et al., Acta Mater. 57, 6123 (2009).

22. Ch. Grossmann et al., Met. Mater. Trans. A 40, 2530 (2009).

23. K. C. Atli et al., Mater. Sci. Eng. A 560, 653 (2013).

24. J. Dadda et al., Int. J. Mater. Res. 101, 1503 (2010). 